\title{
Delirium as the first presentation of lung adenocarcinoma brain metastasis
}

1. Departamento de Psiquiatria e Saúde Mental, Centro Hospitalar Baixo Vouga, Aveiro, Portugal. 2. Hospital Geral, Centro Hospitalar da Universidade de Coimbra, Coimbra, Portugal.

Dear Editor,

A substantial part of patients without significant medical history and who were not previously diagnosed with brain tumors present to the Emergency Department complaining about new symptoms. Tumors metastasizing to the brain account for $15 \%$ to $25 \%$ of all brain tumors ${ }^{1}$. Non-small cell lung cancer (NSCLC) is the most common primary tumor to spread to the brain ${ }^{2}$ and, in rare cases, metastatic tumors may present primarily with acute psychiatric symptoms ${ }^{3}$, which underlines the importance of adequate differential diagnosis when working in Psychiatry Emergency Departments.

We report the clinical case of a patient with no previous psychiatry and medical history, with a subacute onset of delirium, behavioral changes, and reported depressive symptoms, as the first presentation of lung adenocarcinoma brain metastasis.

The patient was a 48-year-old man, smoker, who attended the Emergency Department due to mental confusion, spatiotemporal disorientation, and reported depressive symptoms of subacute onset with anorexia, i.e., weight loss of $8 \mathrm{~kg}$ in the past few months, apparently due to his low mood. Simple laboratory tests were performed and came back normal. Chest X-ray revealed right hilar enlargement.
Our Psychiatry Emergency Unit was requested to attend the patient. He presented a quite incoherent speech and his cognitive performance was grossly affected. His wife reported behavioral changes, with no psychotic symptoms. He had no previous psychiatry and medical history.

An urgent head computerized tomography (CT) scan evidenced multiple space-occupying lesions conditioning mass effect on adjacent structures, compatible with brain metastasis, namely involving the cerebellar hemispheres, right striatocapsular, and temporal region, as well as the bilateral frontoparietal regions, with a notable lesion in the left frontobasal region, of $3.4 \mathrm{~cm}$ diameter. This lesion was accompanied by extensive edema and deviation of the median structures to the right by about $7 \mathrm{~mm}$ (Figure 1).

The patient was hospitalized at the Internal Medicine Ward for etiological study.

During his hospitalization, a chest/abdomen/pelvis CT scan identified multiorgan metastatic disease affecting both lungs, bones (costal, vertebral and iliac metastasis), stomach, and brain, multiple adenopathies (right pulmonary hilum and perigastric) and multinodular thyroid.

Upper digestive endoscopy with biopsy revealed endoscopic lesions compatible with secondary

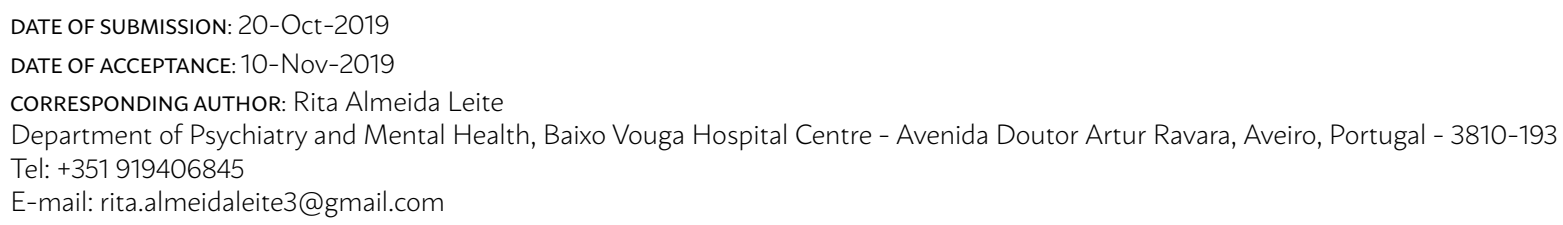


FIGURE 1. HEAD COMPUTERIZED TOMOGRAPHY: LESION IN THE LEFT FRONTOBASAL REGION OF 3.4 CM OF DIAMETER, WITH EXTENSIVE EDEMA AND DEVIATION OF THE MEDIAN STRUCTURES TO THE RIGHT BY APPROXIMATELY $7 \mathrm{MM}$

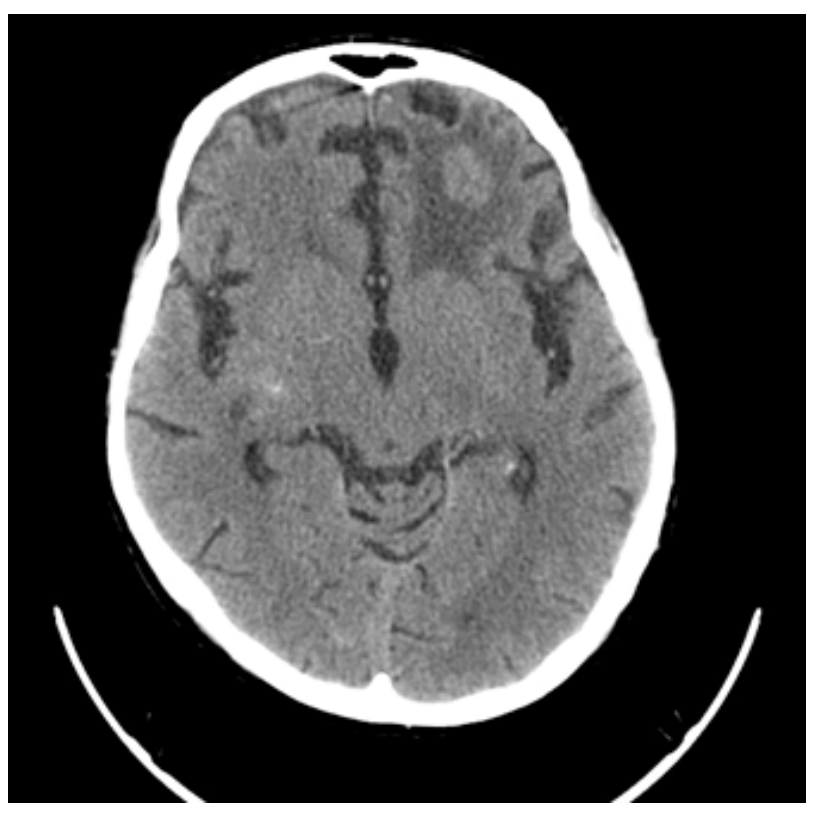

neoplastic involvement of primitive lung adenocarcinoma (CK7 and TTF1 positivity, with negativity for CK 20).

Bone scintigraphy revealed metastatic lesions as well, especially in the iliac.

Finally, genetic tests showed no mutations in the EGFR gene in exons 18, 19, 20, or 21.

From all the studies, it was concluded that the patient had a lung adenocarcinoma with diffuse bony, pulmonary, gastric, and brain metastasis, with no mutations in the EGFR gene. There was no indication for targeted anti-EGFR therapies.

During the hospitalization, the patient remained disoriented, with episodes of psychomotor agitation, despite the therapeutics instituted (maximum doses of haloperidol $10 \mathrm{mg}$ id, olanzapine $10 \mathrm{mg}$ id, chlorpromazine $50 \mathrm{mg}$ id), which motivated physical restraint and difficulted the use of complementary means of diagnosis. After corticotherapy and holocranial radiotherapy (20 Gy in 5 fractions), progressive improvement of the state of consciousness was observed, despite some periods of disorientation that made him dependent when performing basic daily living activities.

At the end of the hospitalization, there was a clinical worsening with sepsis probably due to respiratory infection and MRSA isolation. Despite the measures instituted, the patient died.

A study by Keschner et al. ${ }^{4}$ reported that $78 \%$ of 530 patients with brain tumors had psychiatric symptoms. However, $18 \%$ of the 530 presented only with these symptoms as the first clinical manifestation ${ }^{5}$. According to Mainio et al. ${ }^{5}$, depression was found in $44 \%$ of all brain tumor patients, primary and metastic, and was associated with functional impairment, cognitive dysfunction, reduced quality of life, and reduced survival. Diagnosis of psychiatric symptoms secondary to brain tumors starts from having a clinical suspicion ${ }^{3}$ since an adequate differential diagnosis is key to the early treatment of potentially fatal conditions.

\section{REFERENCES}

1. Price $T R$, Goetz KL, Lovell MR. Neuropsychiatric aspects of brain tumors. In: Yudofsky SC, Hales RE, Snyder SH, eds. The American Psychiatric Publishing textbook of neuropsychiatry and behavioral neurosciences. 5th ed. Arlington: American Psychiatric Publishing; 2007. p.735-64.

2. Ostrom QT, Wright CH, Barnholtz-Sloan JS. Brain metastases: epidemiology. Handb Clin Neurol. 2018;149:27-42.

3. Madhusoodanan S, Ting MB, Farah T, Ugur U. Psychiatric aspects of brain tumors: a review. World J Psychiatry. 2015;5(3):273-85.

4. Keschner M, Bender MB, Strauss I. Mental symptoms associated with brain tumor: a study of 530 verified cases. JAMA. 1938;110(10):714-8.

5. Manio A, Hakko H, Niemelä A, Koivukangas J, Räsänen P. Depression in relation to anxiety, obsessionality and phobia among neurosurgical patients with a primary brain tumor: a 1-year follow-up study. Clin Neurol Neurosurg. 2011;113(8):649-53. 